mitigate potential ENSO climate impacts in the future (see e.g., Fig. 1).

In order to discuss all these aspects, an international workshop on MCEV focusing on analysis, reconstruction and simulation of ENSO related climate oscillations was held in San Diego. The workshop drew more than 20 experts from Australia, Canada, Mexico, Spain, UK and the USA. The participants were mainly researchers from the fields of climate simulations and reconstructions or working on climate impacts and their related economical aspects. This workshop was a complementary meeting to the $10^{\text {th }}$ International Conference on Paleoceanography $\left(10^{\text {th }} I C P\right)$ and was sponsored by the Institute for Mexico and the United States (UC-MEXUS) of the University of California.

Introductory presentations covered a wide range of topics including ENSO modeling, the linear and non-linear trends of climate variability, the differences between local and remote processes, the inherent noise behind the records and their biological feedbacks, GCM projections for the Pacific Decadal Oscillation in the $21^{\text {st }}$ century, ENSO and PDO coincident contributions and trends, and new highresolution geochemistry proxy records. Other aspects also discussed included: MCEV from simulations and proxies, nonlinear decomposition of ENSO simulated records, and orbitally induced mean states of climate change in the Tropical Pacific during interglacials. Emphasis on ENSO climate reconstructions from geological records was provided through an overview of different aspects: (a) on the most adequate archives and the sensitivity of proxy variables linked to ENSO conditions, (b) on the influence of hemispheric climate processes on sea surface temperature (SST) during the Holocene, and (c) on isotopic and geochemical analyses from sedimentary records to determine the transmission of the ENSO signal from the western tropical Pacific and the relationship between ENSO and the California Current variability over the past millennium.

Another session focused on nonlinear mathematical analyses. For example, modeling the millennial synchronization between Greenland and Antarctic $\delta^{18} \mathrm{O}$ records and the non-linear behavior of ENSO on different timescales were discussed.
The concluding session was centered around the regional impacts of ENSO: analysis of inter-annual variability of precipitation and temperatures over Mexico, the social value of climate predictions in terms of public investments, and the reliance on information provided by institutions and organizations.

The next workshops will focus on centennial scale climate forcings (volcanic and solar). Reconstructions, models and their centennial scale forecasts will be discussed taking into account the associated global and regional climate variability.

\section{References}

Emile-Geay, J., Cane, M., Seager, R., Kaplan, A. and Almasi, P., 2008: El Niño as a mediator of the solar influence on climate, Paleoceanography, 22(3), doi: 10.1029/ 2006PA001304.

Loutre, M.F., Berger, A., Bretagnon, P. and Blanc, P.-L., 1992: Astronomical frequencies for climate research at the decadal to century time scale, Climate Dynamics, 7: 181-194.

Mann, M.E., Cane, M.A., Zebiak, S.E. and Clement, A., 2005: Volcanic and Solar Forcing of The Tropical Pacific Over the Past 1000 Years, Journal of Climate, 18: 447-456.

Sánchez-Sesma, J., 2010: Multi-centennial scale analysis and synthesis of an ensemble mean response of ENSO to solar and volcanic forcings, Climate of the Past Discussions, 6: 2055-2069.

Rein, B., Lückge, A., Reinhardt, L., Sirocko, F., Wolf, A. and Dullo, W.-C., 2005: El Niño variability off Peru during the last 20,000 years, Paleoceanography, 20: doi: 10.1029/2004PA001099.

\title{
Linking monsoon systems across timescales
}

\section{$2^{\text {nd }}$ PAGES Global Monsoon Symposium, Shanghai, China, 13-15 September 2010}

\author{
Pinxian Wang ${ }^{1}$, B. WAng ${ }^{2}$, And T. Kiefer ${ }^{3}$ \\ 'State Key Laboratory of Marine Geology, Tongji University, China; pxwang@online.sh.cn \\ ${ }^{2}$ School of Ocean and Earth Science and Technology, University of Hawaii, Honolulu, USA; ${ }^{3}$ PAGES International Project Office, Bern, Switzerland
}

Monsoon systems have earned increasing attention from the climatology community over the past decades, yet remain a subject of regional, if not local studies. Following the first Global Monsoon (GM) meeting in 2008 (see report in PAGES news $17(2), 2009)$, a second meeting was held in an attempt to put regional monsoons into the context of a global system, and to analyze their variations across a range of timescales. A total of 95 participants from 12 countries presented 30 talks and 39 posters.

One focus was the hydrological cycle. In present-day climate, the GM was shown to be coordinated by internal feedback processes such as ENSO variability. An increasing trend in global monsoon precipitation over the last 30 years is attributed to both the effects of global warming and atmosphere-ocean interaction in the Pacific Ocean (B. Wang). However, the link between SST and precipitation is not straightforward (J. Fasullo). In his keynote,

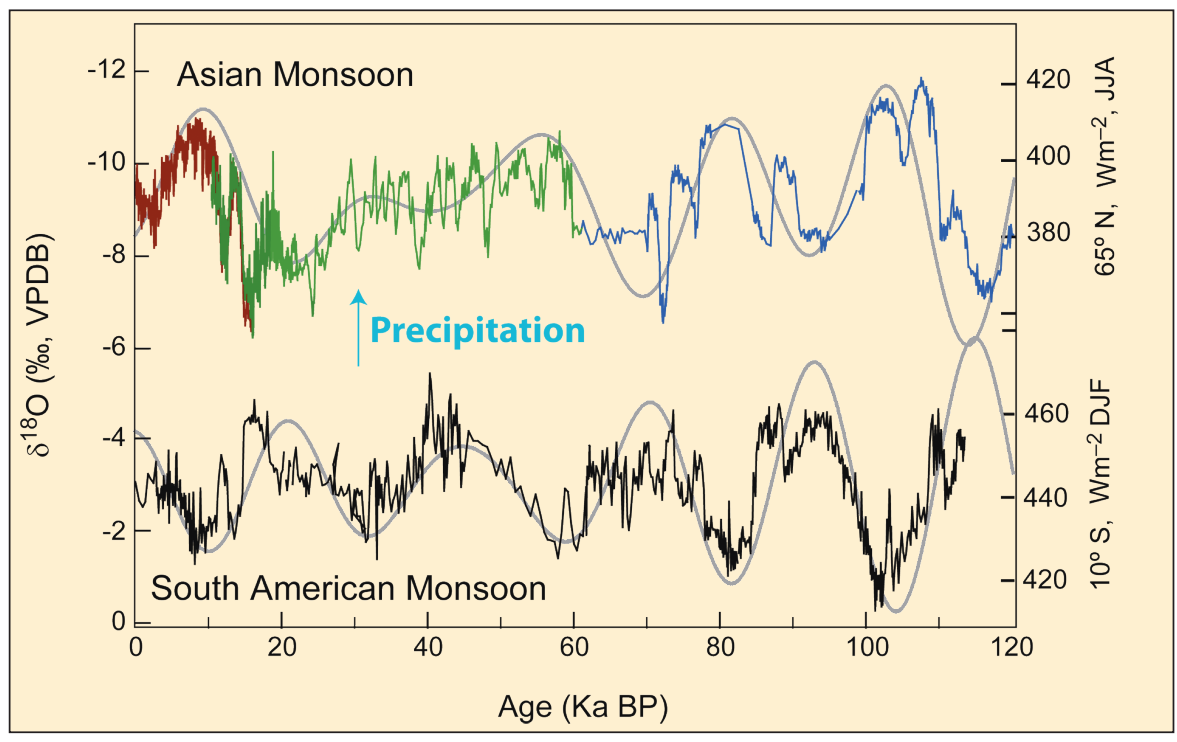

Figure 1: Interhemispheric comparison of changes in monsoon precipitation and summer insolation between eastern Asia and South America. Precipitation changes are reflected in $\delta^{18} \mathrm{O}$ records of speleothem calcite from Dongge cave (brown; Dykoski et al., 2005), Hulu cave (green; Wang et al., 2001), and Sanbao cave (blue; Wang et al., 2008) from eastern China, and from Botuverá cave in southern Brazil (black; Cruz et al., 2005). Insolation data are from (Berger, 1978). Figure courtesy of Hai Cheng.

Peter Webster showed that the area of the (using a fixed criterion of $28^{\circ} \mathrm{C}$ ) increased SST-defined Tropical Ocean Warm Pool by $70 \%$ since 1920 and is expected to oc- 
cupy the entire tropical ocean in 2100 . However, when related to the column integrated heating, the area of the "dynamic warm pool" remained almost unchanged as it is determined by the SST gradient.

Combined data and modeling were used to address monsoon-related hydrological processes, e.g., to demonstrate how monsoon and deserts coexist as twin features of multi-scale forcing (G. Wu). Vegetation feedback modeling simulated that afforestation in monsoon regions cools summers, warms winters and increases spring-summer precipitation locally, but can affect remote climate into an opposite direction (Z. Liu). The use of transient climate simulation in Africa successfully simulated the abrupt start of the African Humid Period in the Sahel and revealed its connection with North Atlantic climate (B. Otto-Bliesner).

The Symposium covered the full range of timescales. Solar cycles, for example, were suggested to have direct and indirect effects on monsoon variations at multi-decadal and centennial timescales (J. Nott; W. Soon), while on centennial timescales the GM strength seems to respond more to the effective solar forcing (J. Liu). Monsoon records from Asia, Africa, and South America could be correlated globally (R. Tada; R. Schneider; F. Cruz; L. Peterson) and compiled oxygen isotope sequences of stalagmites from Asia and South America reveal anti-phasing on orbital, millennial and centennial timescales (H. Cheng; Fig. 1). This provides strong evidence that the GM is connected across hemispheres by the seasonal migration of the ITCZ in response to asymmetrical heat budgets. Global correlation of monsoon records enables us to indentify specific regional features, as demonstrated by the distinct response of the African and Indian monsoons to fresh water flux and ice-sheet forcing during the last glacial ( $P$. Braconnot). On tectonic timescales, steepening of tropical zonal and meridional SST gradients was called upon to explain the aridification of Africa from 2.8-1.6 Ma (P. deMenocal), coherent with the abovementioned monsoon-desert coupling.

Interesting discussions unfolded over monsoon proxies. The hydrogen isotope ratio of fossilized plant wax lipids from marine sediments was presented as an indicator of monsoon precipitation (R. Schneider). Several proxies were proposed to reflect the global monsoon intensity on longer timescales, including inorganic marine carbon isotopes (eccentricity cycles in ocean carbon reservoir), atmospheric methane concentration (tropical wetland extent) and oxygen isotopes of ice-trapped air (Dole effect). The similarity between oxygen isotope records from stalagmites and marine planktonic carbonate in monsoon regions provoked the question whether the oxygen isotope composition of the rainwater had fluctuated together with the GM intensity (P. Wang).

Extreme hydrological events were the final topic of the symposium. A variety of approaches, including sedimentological, geomorphological and isotopic, were introduced to study floods, droughts, and cyclones over the last millennia in Australia and India. Increases in flood frequency were found over the last century, suggesting coherence in the long-term history of the Australia-Asia Monsoon (V. Kale; E. Valentine and B. Wasson).

In summary, the symposium provided not just a global view of regional monsoons, but also a new perspective of the regional monsoons as part of a global system. Just as the high-latitude processes are centered around the poles, so are the low-latitudes processes, represented by monsoon and ENSO, centered at the climatic equator, i.e., the ITCZ. The GM responds directly to external forcing and is modulated by high latitude processes through teleconnections. The next step of the PAGES Global Monsoon Working Group will be a Special Issue of Climate Dynamics followed by a synthesis paper.

\section{References}

Berger, A.L., 1978: Long-term variations of caloric insolation resulting from the Earth's orbital elements, Quaternary Research, 9: 139167.

Dykoski, C.A., et al 2005: A high-resolution, absolute-dated Holocene and deglacial Asian monsoon record from Dongge Cave, China, Earth and Planetary Science Letters, 233: 71-86.

Wang, Y.J., Cheng, H., Edwards, R.L., An, Z.S., Wu, J.Y., Shen, C.C. and Dorale, J.A., 2001: A high-Resolution Absolute-Dated Late Pleistocene Monsoon Record from Hulu Cave, China, Science, 294 2345-2348.

Wang, Y.J., et al., 2008: Millennial-and orbital-scale changes in the East Asian monsoon over the past 224,000 years, Nature, 451 1090-1093.

Cruz, F.W., Burns, S.J., Karmann, I., Sharp, W.D., Vuille, M., Cardoso, A.O., Ferrari, J.A., Dias, P.L.S. and Viana Jr., 0., 2005: Insolation-driven changes in atmospheric circulation over the past 116,000 years in subtropical Brazil, Nature, 434: 63-66.

\title{
Relative sea level, ice sheets and isostasy past, present and future: P A L S E A Understanding the implications for human populations
}

\section{$3^{\text {rd }}$ PALSEA Workshop, Bristol, UK, 20-24 September 2010}

\author{
Morten B. Andersen and Mark Siddall \\ Department of Earth Sciences, University of Bristol, UK; mark.siddall@bristol.ac.uk
}

The joint PAGES-IMAGES Working Group "PALSEA" (Paleo-constraints on sea-level rise; www.climate.unibe.ch/ siddall/ working_group.html) aims to obtain information on climate and sea-level change during the Quaternary period with a multi-disciplinary approach. A better understanding of the relationship between climate, ice-sheet dynamics and sea level is critical for projections of future sea level rise expected from global warming and cannot be achieved using the instrumen- tal record alone. The $3^{\text {rd }}$ PALSEA workshop Relative sea level, ice sheets and isostasy past, present and future (understanding the implications for human populations) was held at University of Bristol.

The workshop was internationally attended by 80 participators from a wide range of sea-level related research areas including ice sheet and climate modelers, geophysicists with expertise in glacial-isostatic adjustment, field scientists engaged in reconstruction of ice-sheet extent and relative sea levels, and marine archeologists. Support was provided by PAGES, IMAGES, the Worldwide Universities Network, UK-Integrated Ocean Drilling Program and the University of Bristol. Scientific presentations and discussions were organized into broad themes of: (1) Predicting future sea-level and ice-sheet evolution (2) Sea level and ice sheets during Termination I (3) Ice sheets: observation and modeling (4) Sea level and ice sheets entering and during warm periods 